\title{
长白山天池火山岩浆系统再认识: 岩石热力学模拟
}

郭文峰 ${ }^{(12)}$, 刘嘉麒 ${ }^{(2 *}$, 徐文刚 ${ }^{(3)}$, 李稳 ${ }^{(4)}$, 雷敏 ${ }^{(1)}$

(1) 中国地质科学院地质研究所, 大陆构造与动力学国家重点实验室, 北京 100037;

(2) 中国科学院地质与地球物理研究所, 新生代地质与环境重点实验室, 北京 100029;

(3) 中国科学院地质与地球物理研究所, 矿产资源研究重点实验室, 北京 100029;

(4) 中国科学院地质与地球物理研究所, 页岩气与地质工程重点实验室, 北京 100029

*联系人, E-mail: liujq@ mail.iggcas.ac.cn

摘要长白山天池火山是一座巨型活火山, 在近代至少发生过数次喷发. 虽然近年来没有再喷 发, 但是有关天池火山再次喷发的争论引起学界广泛关注。岩浆系统的研究是火山灾害和预测 的基础, 主要包括地球物理和岩石学两方面. 综合近年来天池火山岩浆房地球物理探测发现, 普遍认为在火山区中、上地壳存在分布范围较广的岩浆房, 而在中地壳至下地壳也存在范围较 为集中的岩浆存储区. 鉴于地球物理方法具有多解性和不能给出岩浆成分信息等的局限性, 本 文用岩石热力学模拟来约束岩浆房的成分和深度. 结果显示: (1) 天池火山玄武岩在岩石圈地 幔或更深处不能经历斜长石的分离结晶, 可能只经历少量橄榄石的分离结晶; (2) 造盾低 $\mathrm{MgO}$ 玄武岩是原始母岩浆在地壳(约18 27 km, 0.5 0.9 GPa) 中演化后喷出的, 而不是先前认为的从 地幔岩浆房中演化后直接喷出形成的; (3) 粗面质岩浆是由碱性玄武岩在15 18 km (0.5 0.6 GPa, 中上地壳) 结晶分异形成; (4) 天池火山岩浆系统可能要比先前认为的壳幔双层岩浆房模 式复杂, 地壳岩浆系统应该主体为玄武质岩浆, 酸性岩浆只占很小的比例. 这些信息对火山岩 浆系统和喷发预测的研究有重要意义.

长白山火山群坐落于中朝边界(包括天池、望天 鹅、图们江流域和朝鲜境内的胞胎山) 是中国乃至东 北亚典型的板内层状复式火山, 其中天池火山是一 座活火山, 在近代发生过多次喷发. 著名的千年大喷 发(Millennium eruption)形成的喷发柱高达 $25 \mathrm{~km}^{[1]}$, 产生大量火山碎屑流和火山灰. 千年大喷发的火山 灰甚至可以飘到远在 $2000 \mathrm{~km}$ 的Kuril海沟 ${ }^{[2]}$. 虽然近 年来天池火山没有再喷发, 但是火山地震、地壳隆 升、温泉气体活动等一些迹象表明它的活动性并没有 减弱 ${ }^{[3 \sim 6]}$.

火山岩浆系统的研究可以理解岩浆上侵、存储和 喷发的过程, 是降低火山灾害和预测未来喷发研究
的基础. 当前, 火山岩浆系统的研究工作主要包括地 球物理探测和岩石学两个方面. 20 世纪 90 年代以来, 众多的地球物理方法曾尝试过探测天池火山的岩浆 房，也取得了一些成果 ${ }^{[6 \sim 14]}$. 然而，不同探测方法的 结果存在争议(如, 文献 $[8,13]$ ), 而且地球物理方法 也不能确定岩浆房的成分. 岩石学方面, 当前主流观 点为壳幔双层岩浆房的模式 ${ }^{[15]}$, 认为玄武岩类岩石 是在地幔岩浆房中经历橄榄石、单斜辉石、斜长石分 离结晶作用后喷出形成; 而地壳岩浆房主体为粗面 质和碱流质岩浆, 是由玄武质岩浆补给到地壳岩浆 房中经历斜长石、铁橄榄石、钻铁辉石和碱性长石等 矿物的分离结晶演化后形成. 㚞褀诚等人 ${ }^{[15]}$ 认为地 
壳和地幔双层岩浆房具有互动式喷发特点：一方面, 来自地幔的钾质粗面玄武岩浆上升滞留在地壳岩浆 房发生岩浆分离结晶作用和混合作用, 形成双峰式 火山岩分布特征和触发地壳岩浆房的喷发; 另一方 面, 造盾玄武岩浆直接从地幔岩浆房喷出地表, 在天 池火山锥体内外形成诸多小火山渣雉. 魏海泉 ${ }^{[16]}$ 从 物理火山学的角度提出了串珠状的岩浆系统模式, 但没有给出足够的岩石学和地球化学证据. 最新的 岩石地球化学和同位素研究提出下地壳和中上地壳 岩浆房系统中有玄武质岩浆房 ${ }^{[17]}$, 但也缺乏岩浆演 化热力学证据的验证.

由此可见, 无论地球物理学还是岩石学研究对 于天池火山地壳岩浆系统的认识还存在争议和研究 不足. 本文在总结和对比前人地球物理岩浆房探测 结果的基础上, 试图利用已发表的岩石学资料, 运用 结晶岩热力学方法对天池火山岩浆演化过程进行模 拟, 约束其演化的温度和压力等热力学参数. 在此之 上重新认识天池火山岩浆系统, 并试图回答玄武岩 成分主体演化过程到底是在地幔岩浆房还是在地壳 岩浆房中完成, 粗面岩的形成是在下地壳还是在上 地壳. 而这些问题对火山演化和喷发机制的研究有 重要意义.

\section{1 地球物理岩浆房探测}

尽管近年来发表的长白山火山区地球物理的研 究结果不少, 包括天然地震和人工地震、大地电磁测 深、重力等多种方法 ${ }^{[7 \sim 9,11,13,18 \sim 21]}$, 但缺少对火山区结 构和岩浆系统全面的综合总结. 而实际上, 每一种地 球物理方法基于不同的物性差异, 并鉴于其不同的 分辨率和不同的成像技术, 都会造成成像结果的差 别. 本文总结了前人对长白山火山主要的地球物理 岩浆房研究结果 (表1), 并按照深度总结了当前地球 物理对火山区岩浆系统的认识, 指出了地球物理探 测岩浆系统的局限.

\section{1 岩浆存储区的深度、大小、形态}

浅部地壳岩浆系统 $(0 \sim 8 \mathrm{~km})$ 的研究主要通过人 工地震、火山地震和大地电磁测深进行. 人工地震的 研究显示, 在地壳浅部, 深度小于 $8 \sim 9 \mathrm{~km}$ 范围内, $\mathrm{P}$ 波低速体集中分布在天池火山口稍偏北的南北方向 上, 范围较小, 被认为是岩浆喷发过程中的传输通 道, 周围嵌人的高 $\mathrm{P}$ 波速度异常体为残留岩浆系统 ${ }^{[8]}$.
通过研究2002 2003年的火山地震发现, 震源分布在 天池破火口的东北部和西南部, 且沿线性分布, 被认 为是岩浆上侵扰动围岩形成, 火山震源最深达到天 池下方 $5 \mathrm{~km}^{[6]}$. 新近大地电磁研究显示天池火山地下 浅部存在直立型低阻异常区, 至5 8 $\mathrm{km}$ 关闭, 也认 为是火山通道 ${ }^{[21]}$. 在天池火山口下方往北, 深度约 $7 \mathrm{~km}$ 处有明显低阻异常体, 且与火山通道相连 ${ }^{[21]}$. 因此, 天池火山在浅部地壳存在岩浆上侵的通道 $(<5 \mathrm{~km})$, 也有可能存在范围集中的岩浆存储区 $(8 \mathrm{~km})$.

中上地壳岩浆系统(8 20 km): 深部反射地震识 别出火山区地壳存在 $\mathrm{C} 1, \mathrm{C} 2, \mathrm{C} 3$ 和Moho, 4 个速度界 面 ${ }^{[8,27]}$, 本文以 $\mathrm{C} 1, \mathrm{C} 2$ 为界分为上地壳 $(0 \sim 15 \mathrm{~km})$, 中 地壳 $(15 \sim 25 \mathrm{~km})$, 下地壳 $(25 \sim 40 \mathrm{~km}) 3$ 个单元. 人工反 射地震研究显示, 在9 15 km深度范围内, $\mathrm{P}$ 波低速体 的主要特征是分布范围广、尺度大、近似南北走向, 南北延伸80 90 km, 东西向宽度较小, 为30 40 km, 被认为是壳内咜存岩浆的主要位置 ${ }^{[8]}$. 层析成像结果 显示, 在 $10 \mathrm{~km}$ 深度, 明显的 $\mathrm{P}$ 波低速异常体分布在 天池周围, $15 \mathrm{~km}$ 深度上它表现为一个近南北向的 $\mathrm{P}$ 波 低速异常条带 ${ }^{[11]}$. 天池火山地下约 $10 \mathrm{~km}$ 存在低速异 常也被天然地震接受函数研究证实 ${ }^{[9,12]}$, 认为低速体 位于天池火山向南 $30 \mathrm{~km}$, 向北约 $50 \mathrm{~km}$, 顶部在地 下约 $10 \mathrm{~km}$, 低速体厚约 $10 \mathrm{~km}^{[9]}$. 但新的接受函数研 究认为低速体不在天池火山口下方, 而是在天池以 北30 60 km, 深度为地下 10 25 $\mathrm{km}^{[13]}$. 而大地电磁 测深结果显示, 在长白山天池及其以北和以东地区, 约 12 25 $\mathrm{km}$ 深处存在东西宽 5 6 $\mathrm{km}$, 南北宽约 8 $\mathrm{km}^{[7,19]}$. 在长白山北山门附近, 深度7 17 $\mathrm{km}$ 处有直 立型低阻带 ${ }^{[21]}$. 因此, 中部地壳成为岩浆存储的主 要区域, 岩浆体埋深约 $10 \mathrm{~km}$, 厚度5 10 km.

下地壳岩浆系统 $(20 \sim 40 \mathrm{~km})$ : 人工地震的 $\mathrm{N}-\mathrm{S}$ 剖 面显示, 从 $15 \mathrm{~km}$ 深度直至下地壳, 低速体分布特征 表现为横向尺度逐渐缩小 ${ }^{[8]}$. 三维层析成像显示 ${ }^{[11]}$ 随着深度的增加, $\mathrm{P}$ 波低速异常体分布在天池及其西 侧, 其尺度有明显的缩小, 分布范围更加集中, 而且 低速扰动幅度更大. 而大地电磁测深显示在天池火 山口南部约 $20 \mathrm{~km}$, 深度13 30 km之间广泛发育低阻 异常体 ${ }^{[21]}$. 因此, 下地壳也存在岩浆存储区, 其分布 集中于天池火山及其西侧. 对于下地壳至上地幔深 度，尽管早期地震 $\mathrm{CT}$ 实验结果显示在深度为 $38 \sim 65$ 和100 200 km范围存在速度的负异常 ${ }^{[18]}$, 但天然地 震接收函数研究中并未找到 40 60 km存在低速异常 
体 ${ }^{[9,13,20]}$, 还需进一步研究.

需要指出的是, 虽然不同方法给出的地下岩浆 存储区的分布范围, 大小和形态有所差异, 但它们中 间存在一些不容忽视的一致性结果. 在火山区下方 约9 15 km处存在一个范围较广的主岩浆存储区, 在 中地壳和下地壳也存在岩浆存储区. 众所周知, $\mathrm{S}$ 波 相比 $\mathrm{P}$ 波对熔体更为敏感, 将人工地震的 $\mathrm{S}$ 波速度剖 面和接受函数的 $S$ 波剖面对比(图 1) 可见, 9 15和 20 30 km的低速异常区有很好的对应关系. 而在约5 $\mathrm{km}$ 处出现 $\mathrm{S}$ 波速度由高速向低速的拐点, 说明 $5 \mathrm{~km}$ 深度可能是本区上地壳脆性界面, 这与火山地震震 源的深度范围(图1, 文献[6])一致, 指示了岩浆或流 体沿脆性围岩上侵的过程.

\section{2 地球物理的局限性}

地球物理结果的差异大多是其方法本身的局限 性导致的. 首先, 是纵向和横向的空间分辨率和测线 可测深度的局限. 地下岩浆房的尺度通常远大于 $1 \mathrm{~km}$, 因此, 原则上利用人工地震, 可以较为精细地 刻画岩浆体. 但是, 层析成像的实验显示, 异常体的 分辨局限在几公里深度通常是 $1 \sim 3 \mathrm{~km}$, 到中地壳和 下地壳时, 分辨局限增长2 3倍 ${ }^{[28]}$. 其次, 地球物理
的结果具有多解性. 同样的地球物理特点如低速体, 可以是高温也可以是富水或者气体，或者是断裂区 域, 即使都是熔融体也很难给出是玄武质还是粗面 质等的成分信息 ${ }^{[9]}$. 因此, 单靠地球物理解译火山岩 浆系统是不够的, 还必须结合岩石学和地球化学来 约束.

\section{2 岩浆结晶演化热力学模拟}

岩浆中矿物的结晶过程实际上是硅酸盐系统相 反应的过程. 因此, 实验岩石学的研究对理解岩浆矿 物的结晶作用有重要意义 ${ }^{[29]}$. 经典的相图研究曾一 度成为岩石学领域研究的主要工具, 但当体系中相 成分超过三相, 或者体系的热动力变量(温度、压力、 水含量等)较多时，用相图研究非常不便. 而用相律 反应的动力学方程便可用来描述岩浆中的硅酸盐系 统相反应过程 ${ }^{[30]}$. 而知道了某地区火山岩结晶演化 趋势, 也可以反推其岩浆演化过程的热动力条件(如 温度、压力、水含量等). MELTS便是此类热力学模 型算法，它是在大量晶体-液相平衡的实验岩石学数 据的基础上建立的. 在等压-等热的封闭系统计算时, 它可以使系统的Gibbs自由能最小化，进而达到系统 的最稳态; 在对氧逸度或者水传输的开放系统，

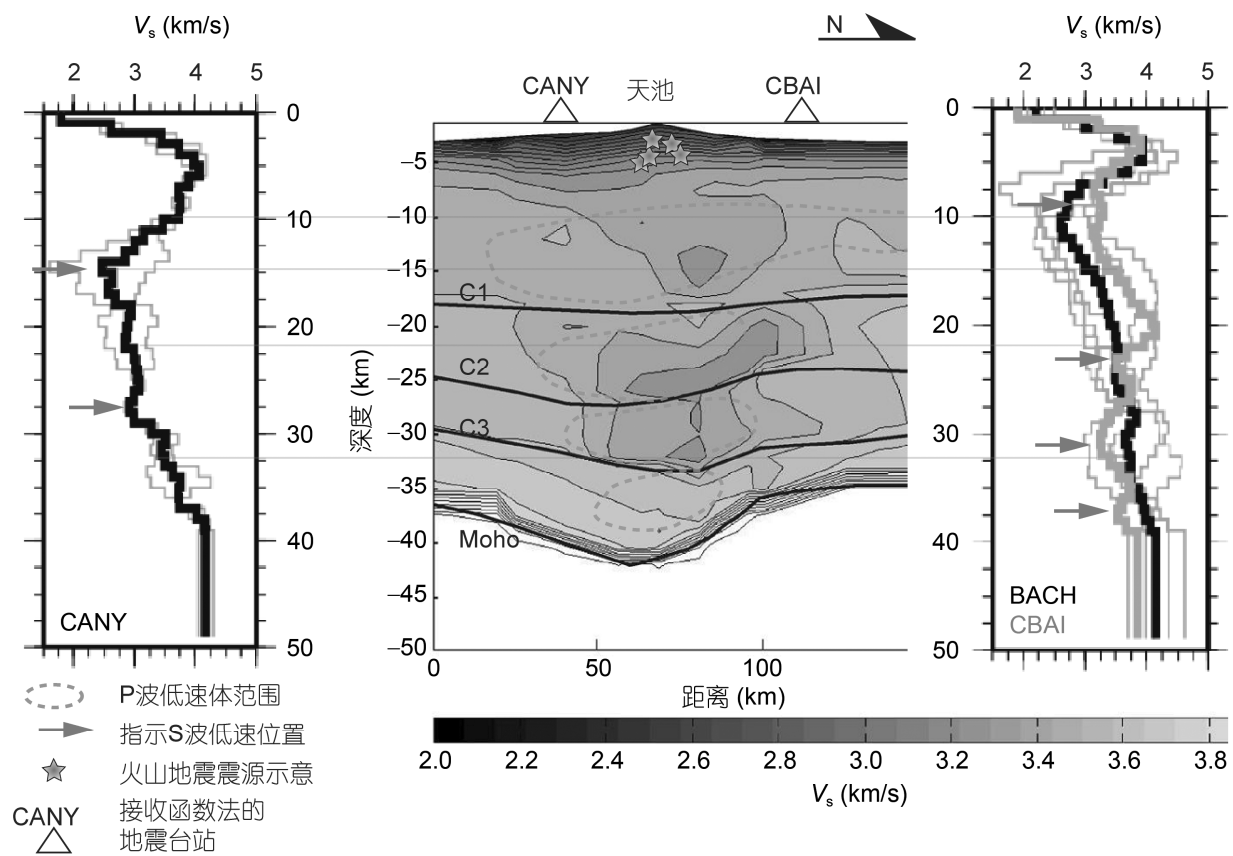

图 1 人工地震和接收函数 S 波探测结果对比(据文献[6,8 10]修改)

Figure 1 A comparison of $S$ wave studies between the active source seismic sounding and receiver functions in the Tianchi volcanic region. Modified from Refs. [6,8-10] 
表 1 天池火山地球物理岩浆房探测结果

Table 1 Summary of geophysical studies on the Tianchi magma reservoirs

\begin{tabular}{|c|c|c|c|}
\hline 方法 & 技术 & 主要结果 & 参考文献 \\
\hline \multirow[t]{9}{*}{ 地震 } & 人工地震 & $\begin{array}{l}\text { 天池火山口下方中下地壳呈现出一倒三角状的P波低速体, 壳内反射界面和莫 } \\
\text { 霍面一致呈下凹形态, 幅度 } 2 \sim 6 \mathrm{~km} \text { 不等, 形成一个地壳根. 在地壳浅部, 深 } \\
\text { 度小于 } 8 \sim 9 \mathrm{~km} \text { 范围内; 在 } 9 \sim 15 \mathrm{~km} \text { 深度, 范围广、尺度大、近南北走向; 自 } 15 \\
\mathrm{~km} \text { 深度以下直至下地壳, 横向尺度较小, 认为岩浆系统极有可能延伸到上 } \\
\text { 地幔, 或更深 }\end{array}$ & {$[8,22]$} \\
\hline & 人工地震层析成像技术 & $\begin{array}{l}\text { 在 } 10 \mathrm{~km} \text { 深度, 明显的 } \mathrm{P} \text { 波低速异常分布在天池周围; } 15 \mathrm{~km} \text { 深度上表现为一个 } \\
\text { 近南北向的 } \mathrm{P} \text { 波低速异常条带, 其延展尺度南北向为 } 80 \sim 90 \mathrm{~km} \text {, 东西向 } \\
30 \sim 40 \mathrm{~km} \text {; 随着深度的增加, } \mathrm{P} \text { 波低速异常分布在天池西侧. 其尺度有明显的 } \\
\text { 缩小, 分布范围更加集中 }\end{array}$ & [11] \\
\hline & 人工地震二维地壳泊松比 & $\begin{array}{l}\text { 火山口下的地壳低速体内有一宽约 } 30 \mathrm{~km} \text { 、高约 } 12 \mathrm{~km} \text { 的高泊松比异常区. 在其 } \\
\text { 下部高泊松比区域, 局部深达莫霍面, 是地幔热物质底侵的可能通道 }\end{array}$ & [10] \\
\hline & 火山地震 & 火山震源最深达到天池下方 $5 \mathrm{~km}$, 被认为是岩浆扰动造成 & [6] \\
\hline & 地震 CT & 深度为38 65 km, 其展布范围约100 200 km的速度的负异常 & {$[18]$} \\
\hline & 天然地震接收函数 & $\begin{array}{l}\text { 天池火山区地壳内部存在明显的 } \mathrm{S} \text { 波低速层, 在离天池火山口附近, 低速层顶 } \\
\text { 部埋深约 } 8 \mathrm{~km} \text {, 厚度近 } 20 \mathrm{~km}, \mathrm{~S} \text { 波最小速度约 } 2.2 \mathrm{~km} / \mathrm{s} \text {. 距离天池越近, 地壳 } \\
\text { 的 } V_{\mathrm{P}} / V_{\mathrm{S}} \text { 越大, 低速层的厚度和幅度增加的特征, 表明天池火山口附近地壳 } \\
\text { 内部存在高温物质或岩浆囊 }\end{array}$ & [20] \\
\hline & 天然地震接收函数 & $\begin{array}{l}\text { 天池火山下方以及天池向南 } 30 \mathrm{~km} \text { 和向北约 } 50 \mathrm{~km} \text {, 顶部在地下约 } 10 \mathrm{~km} \text {, 低速 } \\
\text { 体厚约 } 10 \mathrm{~km}\end{array}$ & {$[9]$} \\
\hline & 天然地震接收函数 & 天池火山地下约 $10 \mathrm{~km}$ 存在明显低速异常 & [12] \\
\hline & 天然地震接收函数 & 天池火山口以北30 60 km, 深度约为地面以下 10 25 km & {$[9,13]$} \\
\hline \multirow[t]{2}{*}{ 电法 } & 大地电磁测深 & $\begin{array}{l}\text { 天池下存在低阻异常区, 深度约为 } 30 \mathrm{~km} \text {, 到天池北部略深于 } 10 \mathrm{~km} \text {, 其中在长 } \\
\text { 白山天池及其以北和以东地区, 约 } 12 \sim 25 \mathrm{~km} \text { 深处存在东西宽 } 5 \sim 6 \mathrm{~km} \text {, 南北 } \\
\text { 宽约 } 8 \mathrm{~km}\end{array}$ & {$[7,19]$} \\
\hline & 大地电磁测深 & $\begin{array}{l}\text { 天池火山下方存在直立型火山通道, 至 } 5 \sim 8 \mathrm{~km} \text { 关闭. 在火山口下方往北, 深度 } \\
\text { 约 } 7 \mathrm{~km} \text { 处有明显低阻异常体, 且与火山通道相连. 在长白山北山门附近, 深 } \\
\text { 度约7 17 } \mathrm{km} \text { 处有直立型低阻带; 在天池火口南部约 } 20 \mathrm{~km} \text {, 深度约 } 13 \sim 30 \\
\mathrm{~km} \text { 之间广泛发育低阻异常体 }\end{array}$ & [21] \\
\hline 重力 & & $\begin{array}{l}\text { 在天池和望天鹅下方形成 } 2 \text { 个负的布格重力异常中心, 天池为 }-16 \times 10^{-5} \mathrm{~m} / \mathrm{s}^{2} \text {, } \\
\text { 望天鹅为 }-32 \times 10^{-5} \mathrm{~m} / \mathrm{s}^{2}\end{array}$ & [23] \\
\hline \multirow[t]{2}{*}{ 形变 } & GPS & 用MOGI模型发现形变符合位于天池火山下7.8 10 km深的单一球形压力源 & {$[24,25]$} \\
\hline & 雷达InSAR & 用MOGI模拟发现两个点源, 天池火山口下方 $7.9 \mathrm{~km}$, 间白山火山下方 $5.5 \mathrm{~km}$ & [26] \\
\hline
\end{tabular}

它可以实现Korzhinki势能和热能的最小化 ${ }^{[31]}$. 目前, 此算法已被广泛应用于基性至酸性岩演化过程的研 究中 ${ }^{[32]}$. 一旦母岩浆、初始系统参数以及岩浆演化约 束条件给定, 便可以通过模拟计算得到岩浆演化过 程和趋势. MELTS适用的压力范围为 $0 \sim 2 \mathrm{GPa}(0 \sim 65$ $\mathrm{km})$, 温度范围为 $500 \sim 2000^{\circ} \mathrm{C}$. 该算法的一个局限是 不能应用于含有富水矿物的岩浆演化 ${ }^{[31]}$. 本文收集 了天池火山近年来发表的岩石学数据, 并删除了烧 失量大于 $2 \%$ 的样品, 应用MELTS算法 ${ }^{[31,33]}$ 来估计岩 浆结晶时的压力.

岩相学研究显示(图2(a)和(b); 文献[34]), 天池 玄武岩斑晶矿物为橄榄石、单斜辉石和斜长石, 其中
高 $\mathrm{MgO}$ 玄武岩中斑晶为橄榄石. 天池火山岩的母岩 浆有碱性玄武岩和拉斑玄武岩两种(图3(a)和(b); 文 献 $[1,16,17,38,43]$ ). 在数据中挑选较原始(高 $\mathrm{Mg}^{\#}$ 和 $\mathrm{Ni}$ 含量)且有代表性的碱性玄武岩(CBS19a)和拉斑玄武 岩(Haku34)的 2 个样品(图3(c)和(d)) 作为母岩浆. 模 拟时玄武岩的氧逸度和含水量参考同构造环境的实 验岩石学条件 ${ }^{[44]}$ : 氧逸度为 QFM-1, 水含量拉斑玄 武岩 $0.3 \%$, 碱性玄武岩为 $0.5 \%$. 根据Zou等人 ${ }^{[45]}$ 的计 算显示, 天池碱流岩结晶的温度约为 $700^{\circ} \mathrm{C}$, 因此, 模拟计算的温度范围为 $1300 \sim 700^{\circ} \mathrm{C}$, 步长为 $10^{\circ} \mathrm{C}$. 据地球物理探测的结果 ${ }^{[8]}$, 天池火山的地壳厚度为 $30 \sim 40 \mathrm{~km}$, 平均为 $35 \mathrm{~km}$ (约 $1.1 \mathrm{GPa}$ ), 上地壳和下地 

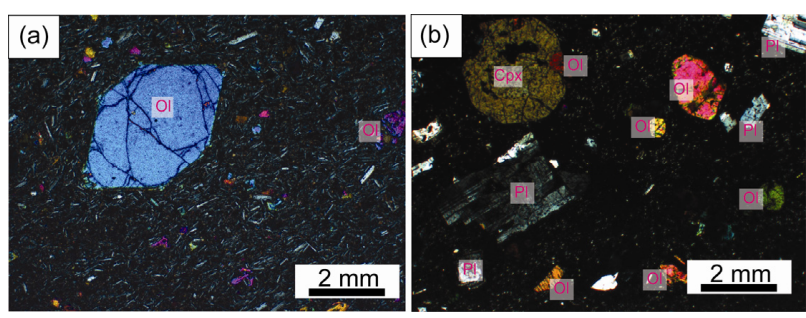

图 2 天池玄武岩代表性岩相图. (a) 高 $\mathrm{MgO}$ 碱性玄武岩; (b) 低 $\mathrm{MgO}$ 粗面玄武岩. $\mathrm{Ol}$, 橄榄石; $\mathrm{Pl}$, 斜长石; $\mathrm{Cpx}$, 单斜辉石

Figure 2 Representative micrographs for Tianchi basalts: (a) high$\mathrm{MgO}$ alkali basalts; (b) low-MgO trachybasalts. Ol, olivine; $\mathrm{Pl}$, plagioclase; Cpx, clinopyroxene

壳以约 $0.7 \mathrm{GPa}($ 约 $21 \mathrm{~km})$ 为界. 为约束天池玄武质岩 浆结晶的深度, 检验壳幔双层岩浆房模式, 选择 0.1 , $0.6,0.9,1.1,1.5 \mathrm{GPa}$ 这 5 个结晶压力分别进行分离结 晶的模拟计算，对于碱性岩浆多加了 $0.5 \mathrm{GPa}$ 的模拟.

模拟计算的结果见图4 6. 从图4(a), (b), 5(b)和 (c)可见, 碱性玄武岩和拉斑玄武岩母岩浆都不能在 地幔深度 $(1.5 \mathrm{GPa})$ 发生主要的分离结晶演化过程, 因为高压下限制了长石的分离结晶导致其 $\mathrm{Al}_{2} \mathrm{O}_{3}$ 明显 偏高和 $\mathrm{K}_{2} \mathrm{O}+\mathrm{Na}_{2} \mathrm{O}$ 偏离天池岩浆演化趋势. 而在低压
下 $(0.1 \mathrm{GPa})$ ，碱性和拉斑玄武岩的演化趋势也偏离 样点趋势 (图4(b) 和 5(b)), 可能是因为斜长石过早的 大量结晶分离，导致 $\mathrm{Al}_{2} \mathrm{O}_{3}$ 过早降低. 拉斑玄武岩合 适的演化压力是 $0.6 \sim 0.9 \mathrm{GPa}$, 且不能分离结晶演化 出富 $\mathrm{K}_{2} \mathrm{O}$ 和 $\mathrm{Na}_{2} \mathrm{O}$ 的碱性岩(图4), 这也符合了一般岩 浆岩的演化规律 ${ }^{[51]}$. 碱性玄武岩在0.5 0.9 $\mathrm{GPa}$ 都可 以发生结晶演化, 但是在 $0.9 \mathrm{GPa}$ (下地壳)时, 当岩浆 成分达到粗面岩时(图4(a)), $\mathrm{SiO}_{2}$ 显示亏损，未达到 $70 \%$, 偏离样点趋势. 因此推测粗面质的岩浆形成于 上地壳，而0.5 0.6 GPa(中上地壳)模拟演化线印证了 这一点(图4(a), (b), 5(a)和(b)). 另外, 模拟结果也支 持碱流岩由碱性粗面岩经低压结晶分异后形成(图 4(a)和 $5(\mathrm{~b}))$.

为进一步检验模拟结果的可信度，将碱性母岩 浆在中地壳 $(0.6 \mathrm{GPa})$ 演化时各氧化物随着温度降低 的变化过程(图6(a)和(b))与主量哈克图结合起来分析 结晶的模拟过程与实际过程符合程度. 在图 6(b)中 $\sim 1180^{\circ} \mathrm{C}$ 时斜长石开始结晶, $\mathrm{Al}_{2} \mathrm{O}_{3}$ 出现拐点, 此位置 对应的 $\mathrm{MgO}$ 为 $5 \%$ 正好对应于 $\mathrm{MgO}-\mathrm{Sr}$ 图上的拐点位 置(图3(d)). 同样, 钾长石开始分离时(图6(b), $\mathrm{K}_{2} \mathrm{O}$ 开始
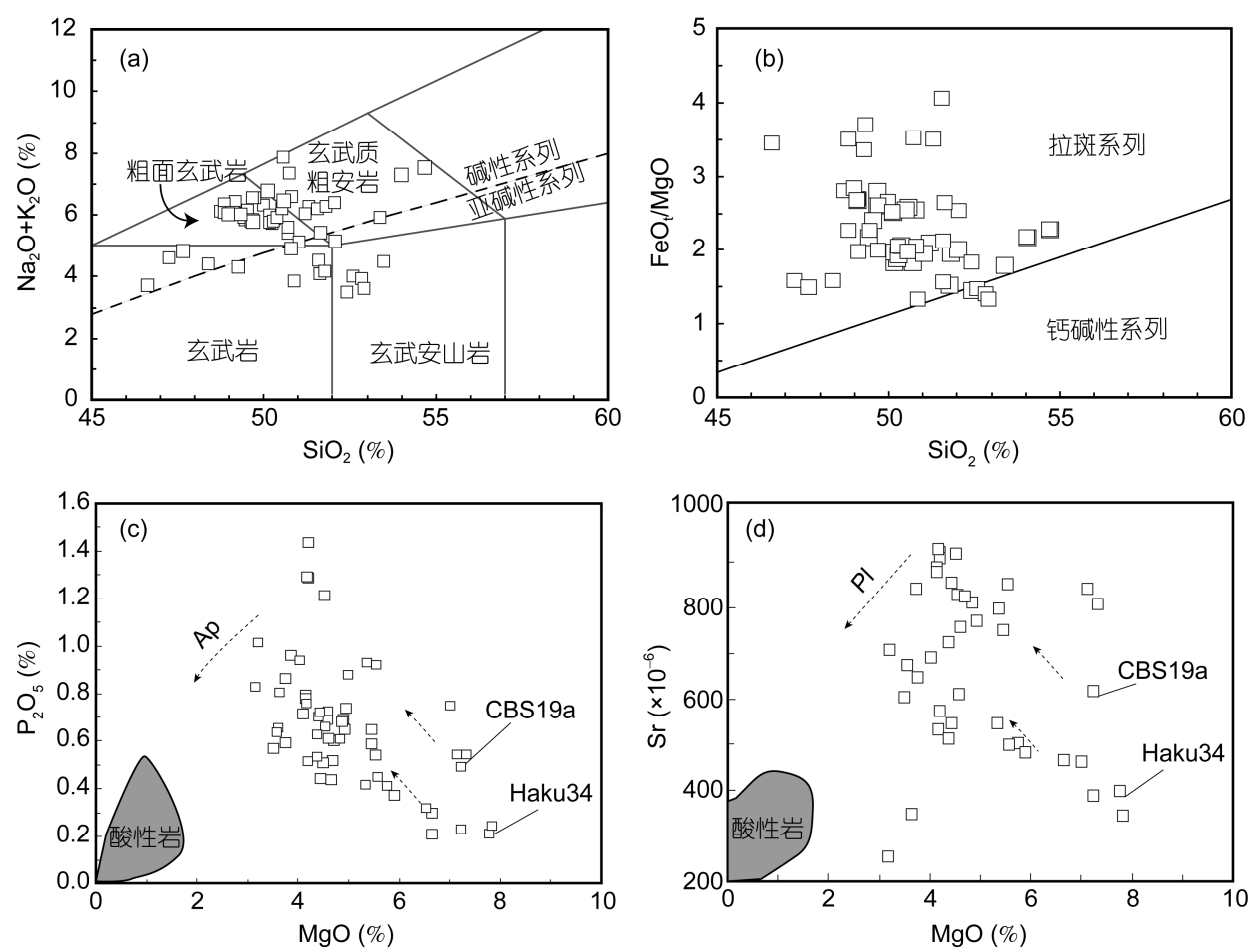

图 3 天池玄武质岩石分类图和主微量二元图. (a)图岩石分类据文献[35,36]; (b)图分类据文献[37]. 数据来源: 文献[17,38 42]. 虚线箭头表示 岩浆分离结晶演化的趋势

Figure 3 Classification and binary diagrams for the Tianchi basaltic rocks. (a) Total alkalies vs. silica, based on $\mathrm{Refs}$. [35,36]; (b) FeO//MgO vs. silica, based on Ref. [37]. Data from Refs. [17,38-42]. The dashed line arrow indicates the evolving trends of the magma 

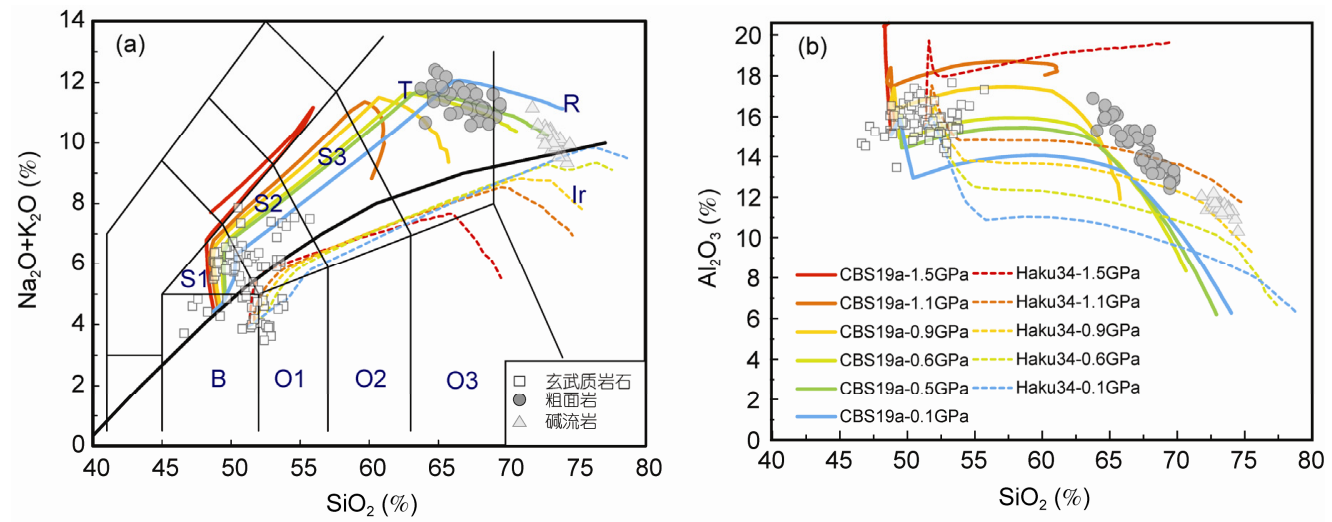

图 4 天池火山岩岩浆演化模拟结果. (a) TAS 图, 分类据文献[37], 岩石类型用字母指代: B, 玄武岩; S1, 粗面玄武岩; S2, 玄武粗面安山岩; $\mathrm{S} 3$, 粗面安山岩; $\mathrm{T}$, 粗面岩; $\mathrm{R}$, 流纹岩; $\mathrm{O} 1$, 玄武安山岩; $\mathrm{O} 2$, 安山岩; $\mathrm{O} 3$, 英安岩; (b) $\mathrm{SiO}_{2}-\mathrm{Al}_{2} \mathrm{O}_{3}$ 图. 数据参考文献 [17,38 42,46 50]

Figure 4 Simulation results of the magmatic fractionational crystallization processes of the Tianchi volcanic rocks. (a) TAS diagrams ${ }^{[37]}$, and (b) $\mathrm{Al}_{2} \mathrm{O}_{3}$ vs. $\mathrm{SiO}_{2}$. Rock types are abbreviated by the following codes: $\mathrm{S} 1$, trachybasalt; $\mathrm{S} 2$, basaltic trachyandesite; $\mathrm{S} 3$, trachyandesite; $\mathrm{T}$, trachyte; O1, basaltic andesite; O2, andesite; O3, dacite. Data sources: Refs. [17,38-42,46-50]
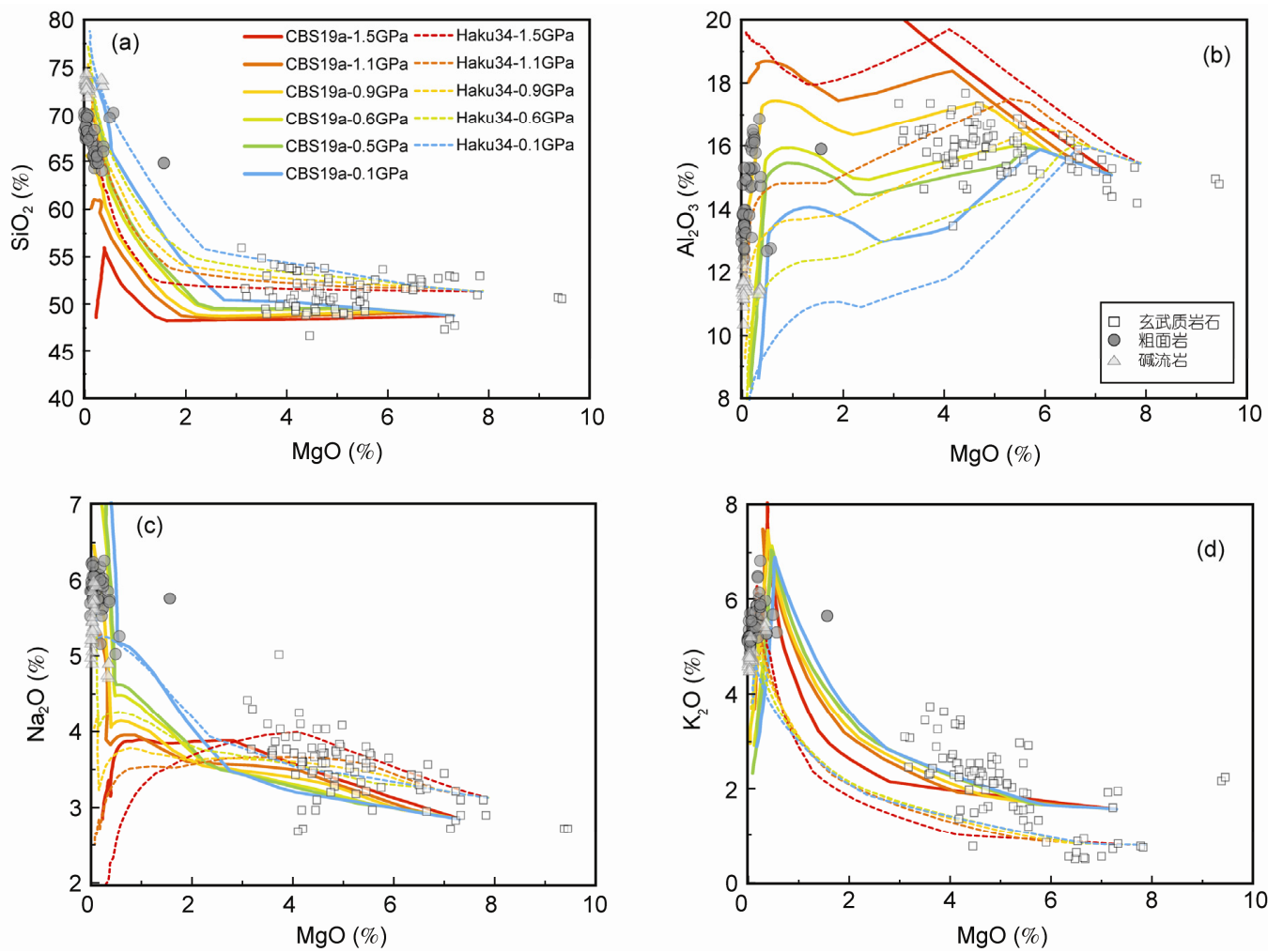

图 5 天池火山岩岩浆演化模拟结果 $\mathrm{MgO}$ 与各氧化物相关关系图

Figure 5 The diagrams of $\mathrm{MgO}$ vs. selected major elements with simulation results of the magmatic fractionational crystalization processes. Solid line, dash line and data sources as in Figure 4

降低)对应的 $\mathrm{MgO}$ 已经接近于 0 也符合图 $5(\mathrm{~d})$ 中 $\mathrm{K}_{2} \mathrm{O}$ 降 低时 $\mathrm{MgO}$ 趋近于 0 . 钛铁矿开始分离时对应 $\mathrm{MgO}$ 为 $3 \%$ 略低于Hark图上对应的4\%(未显示). 而由图6可 知岩浆房中随着温度的降低斑晶的分离结晶顺序为:
橄榄石 $\rightarrow$ 单斜辉石和斜长石 $\rightarrow$ 钛铁矿 $\rightarrow$ 碱性长石. 此顺序也与在岩相学研究 ${ }^{[34]}$ 得到的结论基本一致. 高 $\mathrm{MgO}$ 碱性玄武岩中斑晶只有橄榄石，辉石和斜长 石只在基质中以微晶的形式存在，而在低 $\mathrm{MgO}$ 的造 

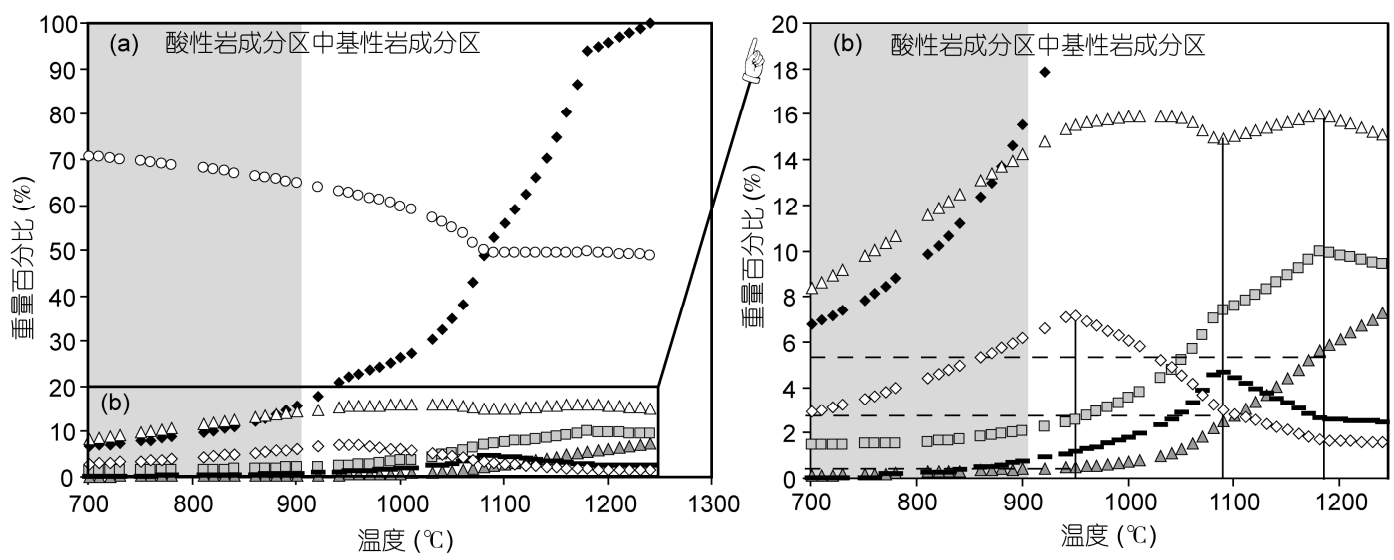

- Mass $(\mathrm{g}) \circ \mathrm{SiO}_{2}(\%) \quad \Delta \mathrm{MgO}(\%) \triangle \mathrm{Al}_{2} \mathrm{O}_{3}(\%) \square \mathrm{CaO}(\%)-\mathrm{TiO}_{2}(\%) \diamond \mathrm{K}_{2} \mathrm{O}(\%)$

图 6 碱性玄武岩于 $0.6 \mathrm{GPa}$ 时分离结晶过程各氧化物含量随温度的变化(a)和局部放大图(b)

Figure 6 (a) Predicted composition variation of alkalic basalt (CBS19a) at $0.6 \mathrm{GPa}$ using the magmatic fractionational crystalization model with (b) a magnified diagram

盾玄武岩中, 斑晶以斜长石为主, 橄榄石、单斜辉次之 (图2(a)和(b)), 这可能表明斜长石较难在原始岩浆所 在的高温、高压的条件下晶出. 而最近, 板内火山岩 的实验岩石学研究也证实了这一点(图7, 文献[44]), 原始岩浆在高温、高压下只结晶橄榄石或橄榄石 + 单 斜辉石, 而斜长石的初始晶出压力要小于 $0.8 \mathrm{GPa}$, 温度要小于约 $1220^{\circ} \mathrm{C}$. 这也与模拟结果一致, 即天池
碱性玄武岩和拉斑玄武岩母岩浆都不能在地幔深 度(1.5 GPa)发生长石的分离结晶. 而同时, 从图7可 见, 在超低压下 $(20.1 \mathrm{GPa})$ 母岩浆会过早的进人斜长 石的主结晶区域, 这也与模拟结果一致(图3(b)), 会 造成 $\mathrm{Al}_{2} \mathrm{O}_{3}$ 过早出现降低趋势与天池火山岩演化趋势 不相符.

因此，最有可能的情况是，天池玄武岩在 $0.5 \sim$

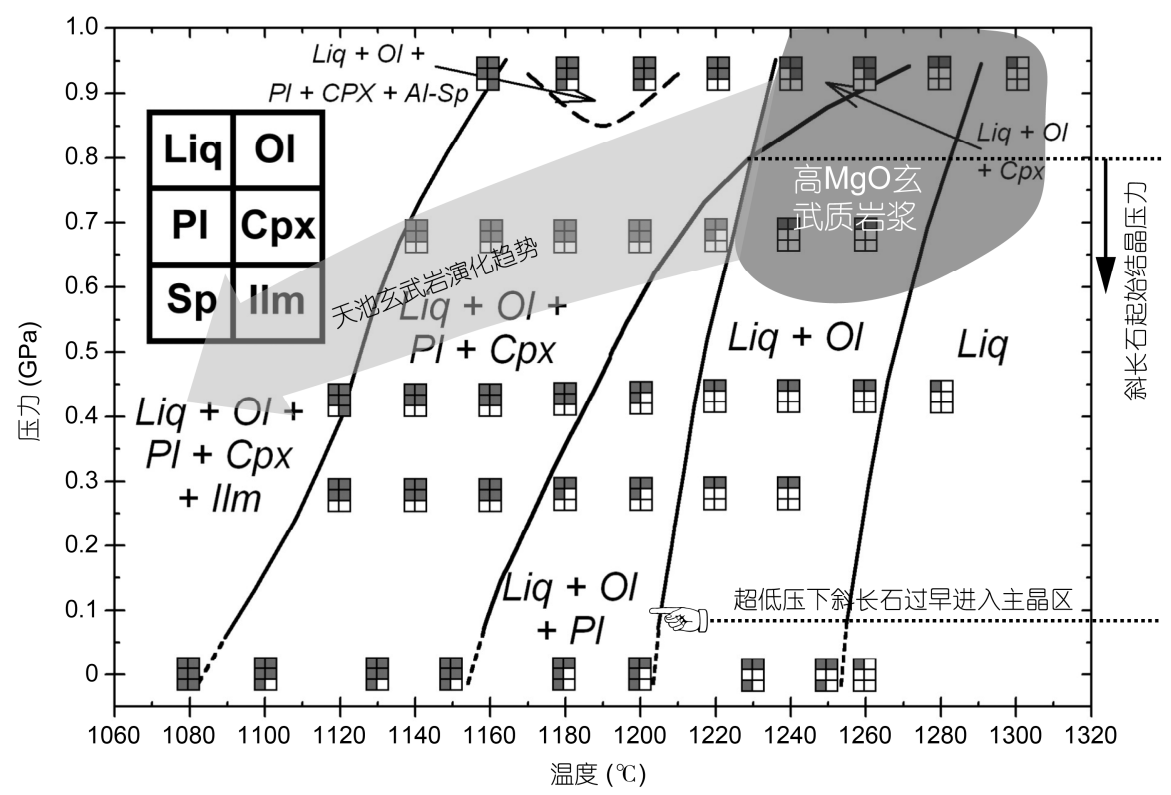

图 7 板内玄武质岩浆实验岩石学 $P-T$ 和矿物相关系(据文献[44]修改). Liq, 液相; Ol, 橄榄石; Pl, 斜长石; Cpx, 单斜辉石; $\mathrm{Sp}$, 尖晶石; Ilm, 钛 铁矿. 深灰色阴影区域为高 $\mathrm{MgO}$ 玄武质母岩浆区域, 浅灰色阴影区域指示出了天池玄武岩可能的演化趋势

Figure 7 The $P$ - $T$ diagram showing phase assemblages of intraplate basaltic magmatic experiments (modifed from Ref. [44]). Liq, liquid; Ol, olivine; $\mathrm{Pl}$, plagioclase; Cpx, clinopyroxene; Sp, spinel; Ilm, ilmenite. The dark gray area indicates the possible region where the primitive magma of the Tianchi starts to evolve, while the light gray arrow shows the evolving trend of the Tianchi basaltic magma 
$0.9 \mathrm{GPa}($ 约15 27 km) 形成下地壳至中上地壳岩浆房 结晶演化; 而只有碱性玄武岩且在约 $0.5 ~ 0.6 \mathrm{GPa}$ (15 18 km, 中上地壳)结晶分异, 演化出天池的粗面 岩. 同时, 模拟结果也与地球物理探测的结果 10 30 $\mathrm{km}$ (图1)中的低速体和高泊松比物质 ${ }^{[9,10]}$ 相互印证.

\section{3 讨论}

岩浆系统的研究是火山喷发机制的一个关键方 面, 因为只有厘清地下岩浆就位深度, 存储区物性成 分等参数后才能建立和预测火山喷发模型. 而目前 学界对天池火山岩浆系统的认识主要依赖于地球物 理的研究结果, 但地球物理方法不能明确给出岩浆 体的成分, 因此, 岩浆系统的成分信息必须由岩石学 的研究来补充. 天池火山岩的特点是: (1) 具有典型 的玄武岩和粗面岩与碱流岩的双峰式岩石组合 ${ }^{[40]}$; (2) 喷发物的主体是大量的低 $\mathrm{MgO}$ (小于 $6 \%$ )玄武岩, 粗面岩和碱流岩的体积还不到 $1 \%{ }^{[23]}$; (3) 粗面岩和碱 流岩与玄武岩有很好的同源演化关系 ${ }^{[38,40,43]}$; (4) 火山 活动跨越了约 $20 \mathrm{Ma}$ 之久, 至今仍在活动 ${ }^{[23,52,53]}$. 前人 提出了壳幔双层岩浆房的模式来解释此岩石组 合 ${ }^{[15,40]}$, 即天池火山下存在地幔和地壳两个岩浆房, 造盾的低 $\mathrm{MgO}$ 玄武岩是在地幔岩浆房中经历橄榄 石、单斜辉石、斜长石分离结晶作用后喷出形成; 而 地壳岩浆房主体为粗面质和碱流质岩浆, 是由玄武 质岩浆补给到地壳岩浆房中经历斜长石、铁橄榄石、 钙铁辉石和碱性长石等矿物的分离结晶演化后喷出 形成. 而最新的玄武质岩石地球化学和同位素研究 认为玄武质岩浆系统的主体应该在地壳 ${ }^{[17]}$, 即低 $\mathrm{MgO}$ 玄武岩是在地壳中经历演化形成的, 因为其同 位素显示出与下地壳和中上地壳混染的趋势. 而解 决这些争论和约束天池火山岩浆系统的关键在于回 答以下几个问题: (1) 天池玄武质岩浆在地幔中能不 能形成岩浆房并发生以橄榄石、单斜辉石、斜长石为 主的分离结晶作用? (2) 如若不能, 则地幔中存在的 低速体如何解释? (3) 如果玄武质岩浆可以在下地壳 和中上地壳形成岩浆房, 则其密度可能大于围岩, 又 作何解释? (4) 粗面岩能不能在下地壳形成岩浆房?

首先, 天池碱性玄武岩不能在地幔中结晶出斜 长石, 因为热动力学模拟显示在高压下 $(1.5 \mathrm{GPa}$, 约 $45 \mathrm{~km}$ ) 碱性玄武岩会无限推迟斜长石结晶位置(图 5(b)中无拐点), 而拉斑玄武质母岩浆虽然可以分离 结晶斜长石但其起始结晶位置 $(\mathrm{MgO}=\sim 4 \%)$ 明显滞后
于天池火山岩所示的位置 $(\mathrm{MgO}=5 \%)$, 导致形成比天 池玄武岩明显富 $\mathrm{Al}_{2} \mathrm{O}_{3}$ 的趋势(图 5(b)). 当然, 模拟结 果不能否认在高压下原始岩浆发生少量的橄榄石土单 斜辉石的分离结晶, 但过多的结晶分离会造成 $\mathrm{K}_{2} \mathrm{O}+$ $\mathrm{Na}_{2} \mathrm{O}$ 和 $\mathrm{SiO}_{2}$ 偏离天池火山岩的演化趋势(图4(a), 5(a) 和(c)). 对于第二个问题, 早期提出的岩石圈地幔存 在岩浆房是基于地震 $\mathrm{CT}$ 结果, 在深度为 $38 \sim 65 \mathrm{~km}$ 存 在速度的负异常 ${ }^{[18]}$, 但最近的天然地震接收函数研 究中并未找到40 50 $\mathrm{km}$ 存在低速异常体 ${ }^{[9,13,20]}$. 如前 所述, $\mathrm{S}$ 波相比 $\mathrm{P}$ 波对熔体更为敏感, 根据吴建平等 ${ }^{[20]}$ S波探测结果, 在天池下 $60 \sim 100 \mathrm{~km}$ 的地幔中存 在大范围的低速体, 而这些低速体并不是岩浆房, 可 能是软流圈地幔高温底辟物质, 或者是源区地幔初 始熔体在未分离前的熔体和残留体的混合物质 ${ }^{[54]}$. 而且, 根据本文模拟的结果, 天池火山岩的演化趋势 不支持玄武质岩浆在岩石圈地幔深度形成稳定的岩 浆房进行大量结晶演化. 对于玄武质岩浆能不能在 下地壳和中上地壳(0.6 0.9 GPa)停留, 这就涉及到岩 浆房形成的一个最基本的问题: 为何会形成岩浆房 而不是直接喷出变成火山岩? 对此, 以前曾有人提 出过著名的中浮面理论, 即当岩浆上升到与围岩密 度相当的层位时, 其所受的浮力为零, 岩浆便不再上 升, 而形成稳定的岩浆房 ${ }^{[55]}$. 但近些年来的研究发 现岩浆停滞的机制并不唯一.上升驱动压力不足, 岩 浆密度太大, 上升岩墙过早冷却停滞, 或岩浆由垂直 上升改为水平运动, 如遇到硬度和密度障碍 ${ }^{[56,57]}$ 等 都会造成岩浆停滞上升. 而在野外可以清楚地看到 玄武质岩浆穿透低密度沉积层的剖面, 也充分说明 密度理论的局限性 ${ }^{[58]}$. 本文倾向于在上升过程中遇 到了硬度界面, 或者是脆性与韧性的界面, 导致玄武 质岩浆的停滞汇集. 另外, 玄武质岩浆的 $\mathrm{Sr}-\mathrm{Nd}-\mathrm{Pb}$ 同 位素研究显示 ${ }^{[17]}$, 天池玄武质岩浆有在下地壳和中 上地壳 $(0.6 \sim 0.9 \mathrm{GPa})$ 停留的痕迹, 而本文的玄武岩演 化热力学模拟结果也支持其在下地壳和中上地壳停 留演化(图4和5). 因此, 地球化学和岩石热力学的证 据都支持玄武质岩浆在地壳中形成岩浆房的假说。 对于粗面质岩浆房的深度问题, 目前的实验数据不 支持天池粗面岩在下地壳形成的观点, 因为其含有 两类碱性长石甚至含有石英 ${ }^{[23]}$, 属于 $\mathrm{Ab}-\mathrm{Or}-\mathrm{Q}-\mathrm{H}_{2} \mathrm{O}$ 演化体系. 实验岩石学研究表明 ${ }^{[59]} \mathrm{Ab}-\mathrm{Or}-\mathrm{Q}-\mathrm{H}_{2} \mathrm{O}$ 体 系中向石英过饱和方向的演化轨迹发生深度小于 0.5 $\mathrm{GPa}$, 约 $15 \mathrm{~km}$. 同时, 热动力学模拟也显示(图4(a)), 


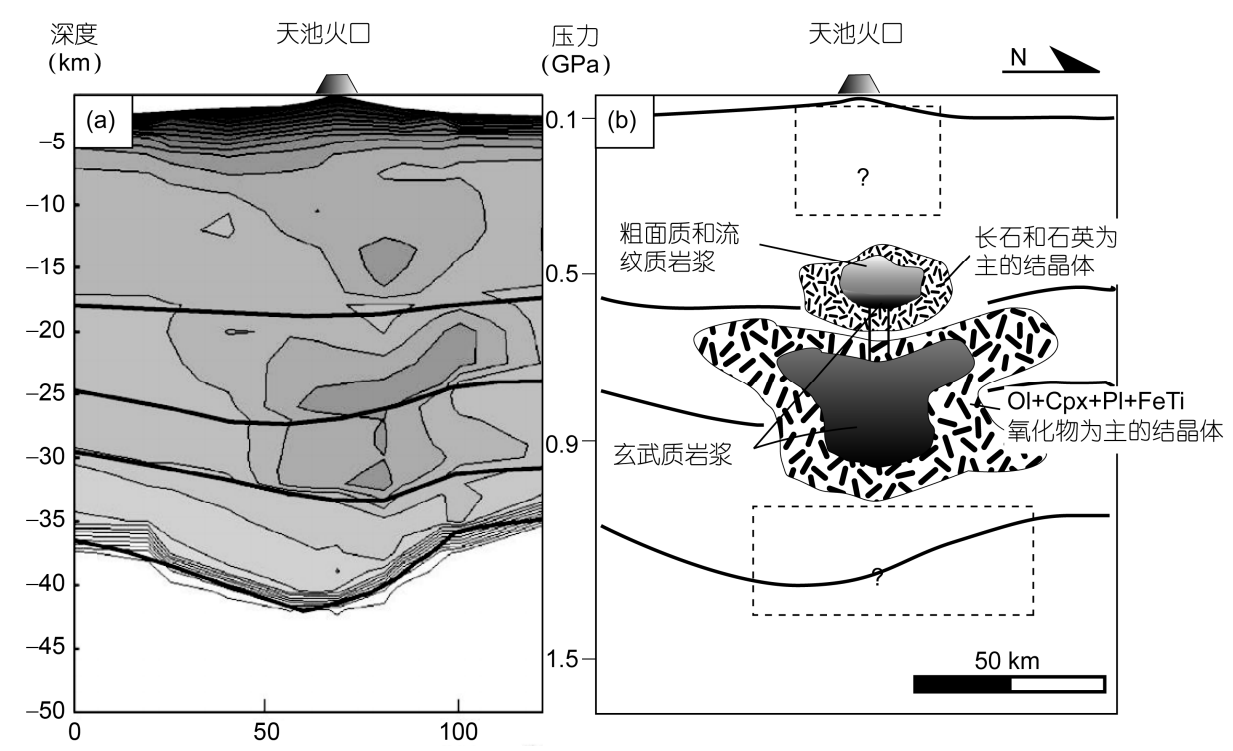

图 8 S 波速度剖面(a)及天池火山地壳岩浆系统模式图(b). (a)据文献[10]

Figure 8 A possible model for the Tianchi magmatic plumbing system based on geophysical imaging (a) ${ }^{[10]}$ and petrological thermodynamics simulation (b)

如果在下地壳演化出粗面岩, 其 $\mathrm{SiO}_{2}$ 含量则会明显 低于天池粗面岩的含量, 所以粗面质岩浆房可能只 存在于上地壳中. 另外, 由图6可见, 单批次的碱性 玄武质母岩浆要结晶出酸性岩浆 $\left(\mathrm{SiO}_{2}>63 \%\right)$ 时, 残 留岩浆的质量减少到小于 $15 \%$, 而到碱流岩时则会 更少. 而根据金伯禄和张希友 ${ }^{[23]}$ 的统计, 天池火山 喷出的酸性岩的量远远小于玄武岩的量，还不到 $1 \%$. 所以天池地壳岩浆系统主体应该为玄武质岩浆, 酸 性岩浆只占很小的比例.

综合起来, 对天池岩浆系统的认识总结如下：玄 武质岩浆起源于软流圈地幔 $(60 \sim 80 \mathrm{~km})$, 在岩石圈地 幔中没有停留, 直接侵人到地壳中驻留演化; 少量含 有地幔包体的岩浆未在地壳中停留直接喷出; 玄武 质岩浆占据下地壳、中上地壳岩浆存储区, 而酸性岩 (粗面岩和碱流岩)只占据了上地壳(图 8); 玄武质岩 浆是天池火山地壳岩浆房的主体, 即存在一个稳定 的玄武质地壳岩浆房, 长期为上地壳酸性岩浆房提
供物质和热量, 使得岩浆有足够的能量, 在对流和水 热循环的消耗之后没有冷却死亡 ${ }^{[60]}$, 反而呈现出长 寿命的特点.

\section{4 结论}

热力学模拟显示, 天池火山玄武岩不能在岩石 圈地幔或更深处分离结晶斜长石. 造盾低 $\mathrm{MgO}$ 玄武 岩的主体演化是在地壳中进行，而在地幔中只经历 少量橄榄石的分离结晶. 天池玄武岩主体演化深度 可能在15 27 km(0.5 0.9 GPa), 而粗面质岩浆是由碱 性玄武岩在15 18 km(0.5 0.6 GPa, 中上地壳)结晶分 异形成.

天池火山岩浆系统可能要比先前认为的壳幔双 层岩浆房模式复杂. 玄武岩可以在地壳中甚至是中 上地壳驻留演化, 且天池地壳岩浆系统主体应该为 玄武质岩浆, 酸性岩浆只占很小的比例. 这些信息对 火山岩浆系统和喷发预测的研究有重要意义.

\section{参考文献}

1 Wei H Q, Liu R X, Li X D. Ignimbrite forming eruptions from Tianchi volcano and their climate effect (in Chinese). Earth Sci Front, 1997, 4: 267-270 [魏海泉, 刘若新, 李晓东. 长白山天池火山造伊格尼姆岩喷发及气候效应. 地学前缘, 1997, 4: 267-270] 
2 Nanayama F, Satake K, Furukawa R, et al. Unusually large earthquakes inferred from tsunami deposits along the Kuril trench. Nature, 2003, 424: 660-663

3 Wu J P, Ming Y H, Zhang H R, et al. Seismic activity at the changbaishan tianchi volcano in the summer of 2002 (in Chinese). Chin J Geophys, 2005, 48: 621-628 [吴建平, 明跃红, 张恒荣, 等. 2002年夏季长白山天池火山区的地震活动研究. 地球物理学报, 2005, 48: 621-628]

4 Stone R. Is China's riskiest volcano stirring or merely biding its time? Science, 2010, 329: 498-499

5 Liu G, Yang J, Wang L, et al. Active level analysis of the Tianchi volcano in Changbaishan, China. Bull Mineral Petrol Geochem, 2011, 30: 393-399

6 Xu J, Liu G, Wu J, et al. Recent unrest of Changbaishan volcano, northeast China: A precursor of a future eruption? Geophys Res Lett, 2012, 39: L16305

7 Tang J, Deng Q H, Zhang G Z, et al. Electric conductivity and magma chamber at the Tianchi volcano area in Changbaishan Mountain (in Chinese). Seismol Geol, 2001, 23: 191-200 [汤吉, 邓前辉, 赵国泽, 等. 长白山天池火山区电性结构和岩浆系统. 地震地质, 2001, 23: 191-200]

8 Zhang X K, Zhang C K, Zhao J R, et al. Deep seismic sounding investigation into the deep structure of the magma system in ChangbaishanTianchi volcanic region. Acta Seimol Sin, 2002, 15: 143-151

9 Hetland E A, Wu F T, Song J L. Crustal structure in the Changbaishan volcanic area, China, determined by modeling receiver functions. Tectonophysics, 2004, 386: 157-175

10 Liu Z, Zhang X K, Wang F Y, et al. 2-D crustal poisson's ratio from seismic travel time inversion in Changbaishan Tianchi volcanic region (in Chinese). Acta Seimol Sin, 2005, 27: 324-331 [刘志, 张先康, 王夫运, 等. 用地震走时反演计算长白山天池火山区二维地 壳泊松比. 地震学报, 2005, 27: 324-331]

11 Yang Z X, Zhang X K, Zhao J R, et al. Tomographic imaging of 3-D crustal structure beneath Changbaishan-Tianchi volcano region (in Chinese). Chin J Geophys, 2005, 48: 107-115 [杨卓欣, 张先康, 赵金仁, 等. 长白山天池火山区三维地壳结构层析成像. 地球物理 学报, 2005, 48: 107-115]

12 Duan Y H, Zhang X K, Liu Z, et al. A study on crustal structures of Changbaishan-Jingpohu volcanic area using receiver functions (in Chinese). Chin J Geophys, 2005, 48: 352-358 [段永红, 张先康, 刘志, 等. 长白山-镜泊湖火山区地壳结构接收函数研究. 地球物理 学报, 2005, 48: 352-358]

13 Song J, Hetland E A, Wu F T, et al. P-wave velocity structure under the Changbaishan volcanic region, NE China, from wide-angle reflection and refraction data. Tectonophysics, 2007, 433: 127-139

14 Ji L, Xu J, Wang Q, et al. Episodic deformation at Changbaishan Tianchi volcano, northeast China during 2004 to 2010 , observed by persistent scatterer interferometric synthetic aperture radar. J Appl Remote Sens, 2013, 7: 073499, doi: 10.1117/1.JRS.7.073499

15 Fan Q C, Sui J L, Li N, et al. The magmatism and interactive eruption of the two magma chambers in the Tianchi volcano, Changbaishan (in Chinese). Bull Mineral Petrol Geochem, 2007, 26: 315-318 [樊祺诚, 隋建立, 李霓, 等. 长白山天池火山双岩浆房岩浆作用与互 动式喷发. 矿物岩石地球化学通报, 2007, 26: 315-318]

16 Wei H Q. Magma up-moving process within the magma prism beneath the Changbaishan volcanoes (in Chinese). Earth Sci Front, 2010, 17: 11-23 [魏海泉. 长白山火山岩浆柱岩浆上升作用过程. 地学前缘, 2010, 17: 11-23]

17 Guo W F, Liu J Q, Guo Z F. Temporal variations and petrogenetic implications in Changbai basaltic rocks since the pliocene (in Chinese). Acta Petrol Sin, 2014, 30: 3595-3611 [郭文峰, 刘嘉麒, 郭正府. 长白山上新世以来玄武岩成分演变规律及其成因. 岩石学报, 2014, 30: 3595-3611]

18 Guo L C, Ma S Z, Zhang Y S. Research on magma chamber of Changbai mountain volcanoes by means of seismic tomography (in Chinese). CT Theory Appl, 1996, 5: 47-52 [郭履灿, 马石庄, 张禹慎. 应用地震CT技术研究长白山火山的岩浆囊. CT理论与应用研 究, 1996, 5: 47-52]

19 Tang J, Zhao G Z, Wang J J, et al. Study of the formation mechanism for volcanism in northeast China based on deep electric structure (in Chinese). Acta Petrol Sin, 2006, 22: 1503-1510 [汤吉, 赵国泽, 王继军, 等. 基于地下电性结构探讨中国东北活动火山形成机制. 岩 石学报, 2006, 22: 1503-1510]

20 Wu J P, Ming Y H, Su W, et al. S-Wave velocity structure beneath Changbaishan Tianchi volcano inferred from receiver function (in Chinese). Seismol Geol, 2009, 31: 584-597 [吴建平, 明跃红, 苏伟, 等. 长白山火山区壳幔S波速度结构研究. 地震地质, 2009, 31: 584-597]

21 Qiu G G, Pei F G, Fang H, et al. Analysis of magma chamber at the Tianchi volcano area in Changbai mountain (in Chinese). Chin J Geophys, 2014, 57: 3466-3477 [仇根根, 裴发根, 方慧, 等. 长白山天池火山岩浆系统分析. 地球物理学报, 2014, 57: 3466-3477]

22 Wang F Y, Zhang X K, Yang Z X. 2-D crustal structure of Changbaishan-Tianchi volcanic region determined by seismic travel time inversion (in Chinese). Acta Seimol Sin, 2002, 24: 144-152, 223 [王夫运, 张先康, 杨卓欣. 用地震走时反演长白山天池火山地区的 二维地壳结构. 地震学报, 2002, 24: 144-152, 223] 
23 Jin B L, Zhang X Y. Researching Volcanic Geology in Changbai Mt Northeast Korea (in Chinese). Yanbian: Nation Education Press, 1994. 1-223 [金伯禄, 张希友. 长白山火山地质研究. 延边: 东北朝鲜民族教育出版社, 1994. 1-223]

24 Cui D X, Wang Q L, Li K, et al. Analysis of recent deformation of Changbaishan Tianchi volcano (in Chinese). Chin J Geophys, 2007, 50: 1731-1739 [崔笃信, 王庆良, 李克, 等. 长白山天池火山近期形变场演化过程分析. 地球物理学报, 2007, 50: 1731-1739]

25 Hu Y X, Wang Q L, Cui D X, et al. Application of Mogi model at Changbaishan Tianchi volcano (in Chinese). Seismol Geol, 2007, 29: 144-151 [胡亚轩, 王庆良, 崔笃信, 等. Mogi模型在长白山天池火山区的应用. 地震地质, 2007, 29: 144-151]

26 Chen G H, Shan X J, Moon W M, et al. A modeling of the magma chamber beneath the changbai mountains volcanic area constrained by InSAR and GPS derived deformation (in Chinese). Chin J Geophys, 2008, 51: 1085-1092 [陈国湤, 单新建, Moon W M, 等. 基于 InSAR、GPS形变场的长白山地区火山岩浆囊参数模拟研究. 地球物理学报, 2008, 51: 1085-1092]

27 Zhang C K, Zhang X K, Zhang J R, et al. Study on the crustal and upper mantle structure in the Tianchi volcanic region and its adjecent area of Changbaishan (in Chinese). Chin J Geophys, 2002, 45: 812-820 [张成科, 张先康, 赵金仁, 等. 长白山天池火山区及邻近地区 壳幔结构探测研究. 地球物理学报, 2002, 45: 812-820]

28 Martí J, Geyer A, Folch A, et al. A review on collapse caldera modelling. Develop Volcanol, 2008, 10: 233-283

29 Deng J F. Phase Equilibrium and Petrogenesis of Rocks (in Chinese). Wuhan: Press of Wuhan College of Geology, 1987. 1-198 [邓晋福. 岩石相平衡与岩石成因. 武汉: 武汉地质学院出版社, 1987. 1-198]

$30 \mathrm{Ma} \mathrm{H}$ W. Introduction to Thermodynamics in Crystalline Petrology (in Chinese). 2nd ed. Beijing: Higher Education Press, 2001. 1-588 [马鸿文. 结晶岩热力学概论. 第二版. 北京: 高等教育出版社, 2001. 1-588]

31 Ghiorso M S, Sack R O. Chemical mass transfer in magmatic processes IV. A revised and internally consistent thermodynamic model for the interpolation and extrapolation of liquid-solid equilibria in magmatic systems at elevated temperatures and pressures. Contrib Mineral Petrol, 1995, 119: 197-212

32 Thompson R N, Riches A J V, Antoshechkina P M, et al. Origin of CFB magmatism: Multi-tiered intracrustal picrite-rhyolite magmatic plumbing at Spitzkoppe, Western Namibia, during Early Cretaceous Etendeka Magmatism. J Petrol, 2007, 48: 1119-1154

33 Asimow P D, Ghiorso M S. Algorithmic modifications extending MELTS to calculate subsolidus phase relations. Am Miner, 1998, 83: $1127-1131$

34 Wei H Q. Tianchi Volcano, Changbaishan (in Chinese). Beijing: Seismological Press, 2014. 1-448 [魏海泉. 长白山天池火山. 北京: 地 震出版社, 2014. 1-448]

35 Irvine T, Baragar W. A guide to the chemical classification of the common volcanic rocks. Can J Earth Sci, 1971, 8: 523-548

36 Le Bas M J, Le Maitre R, Streckeisen A, et al. A chemical classification of volcanic rocks based on the total alkali-silica diagram. J Petrol, 1986, 27: 745-750

37 Miyashiro A. Volcanic rock series in island arcs and active continental margins. Am J Sci, 1974, 274: 321-355

38 Hsu C N, Chen J C, Ho K S. Geochemistry of Cenozoic volcanic rocks from Kirin Province, northeast China. Geochem J, 2000, 34: 33-58

39 Chen Y, Zhang Y, Graham D, et al. Geochemistry of Cenozoic basalts and mantle xenoliths in Northeast China. Lithos, 2007, 96: 108-126

40 Fan Q C, Sui J L, Wang T H, et al. History of volcanic activity, magma evolution and eruptive mechanisms of the Changbai Volcanic Province (in Chinese). Geol J China Univ, 2007, 13: 175-190 [焚祺诚, 隋建立, 王团华, 等. 长白山火山活动历史、岩浆演化与喷发 机制探讨. 高校地质学报, 2007, 13: 175-190]

41 Sun C Q. Study on Characteristics of Petrology and Magma Evolution of the Tianchi Volcano in Changbai Mountain (in Chinese). Master Dissertation. Beijing: Institute of Geology, China Earthquake Administration, 2008 [孙春强. 长白山天池火山岩石学与岩浆演化特征 研究. 硕士学位论文. 北京: 中国地震局地质研究所, 2008]

42 Kuritani T, Kimura J, Miyamoto T, et al. Intraplate magmatism related to deceleration of upwelling asthenospheric mantle: Implications from the Changbaishan shield basalts, northeast China. Lithos, 2009, 112: 247-258

43 Tian F, Tang D P. Petrogenesis of the Cenozoic volcanic rocks in the Changbaishan region (in Chinese). Acta Petrol Sin, 1989, 5: 49-64 [田丰, 汤德平. 吉林省长白山地区新生代火山岩的特点及其成因. 岩石学报, 1989, 5: 49-64]

44 Whitaker M, Nekvasil H, Lindsley D, et al. The role of pressure in producing compositional diversity in intraplate basaltic magmas. J Petrol, 2007, 48: 365-393

45 Zou H B, Fan Q C, Zhang H F, et al. U-series zircon age constraints on the plumbing system and magma residence times of the Changbai volcano, China/North Korea border. Lithos, 2014, 200: 169-180

46 Xie G H, Wang J W, Basu A R, et al. Petrochemistry and Sr, Nd, Pb-isotopic geochemistry of Cenozoic volcanic rocks, Changbaishan area, Northeast China (in Chinese). Acta Petrol Sin, 1988, 4: 1-13 [解广轰, 王俊文, Basu A R, 等. 长白山地区新生代火山岩的岩石 化学及 $\mathrm{Sr}, \mathrm{Nd}, \mathrm{Pb}$ 同位素地球化学研究. 岩石学报, 1988, 4: 1-13]

47 Fan Q C, Liu R X, Wei H Q, et al. Petrogeochemical characteristics of Holocene eruption of the Tianchi volcano, Changbai Mountains (in Chinese). Geol Rev, 1999, 45: 263-271 [樊祺诚, 刘若新, 魏海泉, 等. 长白山天池火山全新世喷发与岩石地球化学特征. 地质论评, 1999, 45: 263-271] 
48 Wei H Q, Li C M, Jin B L, et al. The Tianchi forming cone eruptive magmatic evolutionary series of the Changbaishan and stratigraphic division (in Chinese). Jinlin Geol, 2005, 24: 22-27 [魏海泉，李春茂，金伯禄，等. 长白山天池火山造雉喷发岩浆演化系列与地层划 分. 吉林地质, 2005, 24: 22-27]

49 Shi Y S. Study on Characteristics and Petrogenesis of Qixiangzhan Stage Lava Flow of Tianchi Volcano, Changbaishan (in Chinese). Master Dissertation. Beijing: Capital Normal University, 2007 [史延升. 长白山天池火山气象站期晚期碱流质熔岩流的特征及其成因. 硕士学位论文. 北京: 首都师范大学, 2007]

50 Zou H, Fan Q, Yao Y. U-Th systematics of dispersed young volcanoes in NE China: Asthenosphere upwelling caused by piling up and upward thickening of stagnant Pacific slab. Chem Geol, 2008, 255: 134-142

51 Gill R. Igneous Rocks and Processes: A Practical Guide. Oxford: John Wiley \& Sons, 2010. 1-552

52 Liu J Q, Wang S S. Age of Changbaishan volcano and Tianchi lake. Chin Sci Bull, 1984, 29: 229-232 [刘嘉麒，王松山。长白山火山与 天池的形成时代. 科学通报, 1982, 21: 1312-1315]

53 Liu J Q. Study on geochronology of the Cenozoic volcanic rocks in Northeast China (in Chinese). Acta Petrol Sin, 1987, 3: 21-31 [刘嘉 麒. 中国东北地区新生代火山岩的年代学研究. 岩石学报, 1987, 3: 21-31]

54 Wilson B M. Igneous Petrogenesis a Global Tectonic Approach. Berlin: Springer Science \& Business Media, 1989

55 Ryan M P. Neutral buoyancy and the mechanical evolution of magmatic systems. Magmatic Processes: Physicochemical Principles. Geochem Soc Univ Park, 1987. 259-287

56 Kavanagh J L, Menand T, Sparks R S J. An experimental investigation of sill formation and propagation in layered elastic media. Earth Planet Sci Lett, 2006, 245: 799-813

57 Taisne B, Jaupart C. Dike propagation through layered rocks. J Geophys Res-Solid Earth, 2009, 114, doi: 10.1029/2008JB006228

58 Taisne B, Tait S. Eruption versus intrusion? Arrest of propagation of constant volume, buoyant, liquid-filled cracks in an elastic, brittle host. J Geophys Res-Solid Earth, 2009, 114, doi: 10.1029/2009JB006297

59 Blundy J, Cashman K. Petrologic Reconstruction of magmatic system variables and processes. Rev Mineral Geochem, 2008, 69: 179-239

60 Annen C. From plutons to magma chambers: Thermal constraints on the accumulation of eruptible silicic magma in the upper crust. Earth Planet Sci Lett, 2009, 284: 409-416

\title{
Reassessment of the magma system beneath Tianchi volcano, Changbaishan: Phase equilibria constraints
}

\author{
GUO WenFeng ${ }^{1,2}$, LIU JiaQi ${ }^{2}$, XU WenGang ${ }^{3}$, LI Wen ${ }^{4} \&$ LEI Min ${ }^{1}$ \\ ${ }^{1}$ Key Laboratory of Continental Tectonics and Dynamics, Institite of Geology, Chinese Academy of Geological Sciences, Beijing 100037, China; \\ ${ }^{2}$ Key Laboratory of Cenozoic Geology and Environment, Institute of Geology and Geophysics, Chinese Academy of Sciences, Beijing 100029, \\ China; \\ ${ }^{3}$ Key Laboratory of Mineral Resource, Institute of Geology and Geophysics, Chinese Academy of Sciences, Beijing 100029, China; \\ ${ }^{4}$ Key Laboratory of Shale Gas and Geoengineering, Institute of Geology and Geophysics, Chinese Academy of Sciences, Beijing 100029, China
}

The depths of magma storage regions are critical for understanding the magma plumbing system and magma evolving processes, and are studied and constrained mainly using geophysical and petrological techniques. In this study, we review the geophysical studies that in recent years, focused on the Tianchi magma reservoirs and find that several studies consistently reported the existence of a wide magma storage region at about $10-15 \mathrm{~km}$ depth that narrows down to $15-40 \mathrm{~km}$, under the Tianchi volcano. To provide an independent constraint, we used petrological thermodynamics simulation (phase equilibria) to reconstruct the depth and composition of the Tianchi volcano magma chamber. The results show that: (1) the Tianchi primitive magma may not have plagioclase fractional crystallized in the lithospheric mantle or deeper, and may only experienced a small degree of olivine fractional crystallization; (2) the lower $\mathrm{MgO}$ shield basalts erupted from the magma chamber that is located in the earth's crust (18-27 km, 0.5-0.9 GPa), instead of being directly ejected from the lithospheric mantle as it was assumed previously; (3) the trachytic magma is stored at depth of about 15-18 km (0.5-0.6 GPa, in the upper crust) and evolved from alkali basalt; (4) the Tianchi volcanic magmatic system may be more complicated than previously thought. The basaltic magma should occupy the main crustal magma reservoirs, from the lower to the mid-upper crust, while the acidic magma accounts for only a very small proportion and is concentrated in the upper crust.

\section{Changbaishan, Tianchi volcano, magma system, petrological thermodynamics simulation}

doi: 10.1360/N972015-00487 